\title{
Tariff-Mediated Network Effects versus Strategic Discounting: Evidence from German Mobile Telecommunications
}

\author{
Leon Zucchini Jörg Claussen Moritz Trüg
}

Discussion Paper 2012-01

April 2013

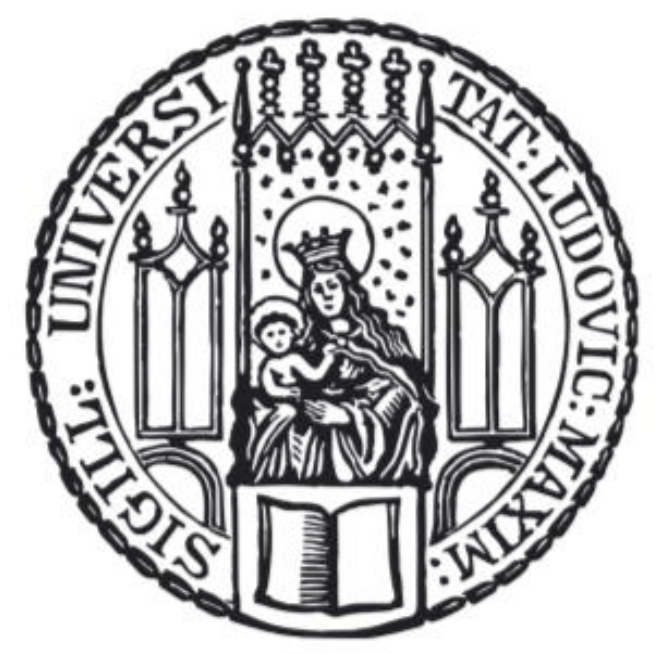

Munich School of Management

University of Munich

Fakultät für Betriebswirtschaft

Ludwig-Maximilians-Universität München

Online at http://epub.ub.uni-muenchen.de 


\title{
Tariff-Mediated Network Effects versus Strategic Discounting: Evidence from German Mobile Telecommunications
}

\author{
Leon Zucchini ${ }^{\mathrm{a}, 1}$, Jörg Claussen ${ }^{\mathrm{b}}$, Moritz Trüg ${ }^{\mathrm{a}}$ \\ ${ }^{a}$ Munich School of Management, Ludwig-Maximilians-Universität Munich, Schackstrasse 4/III, D-80539 Munich \\ ${ }^{b}$ Copenhagen Business School, Kilevey 14, 2000 Frederiksberg, Denmark
}

Forthcoming, International Journal of Industrial Organization

April 2013

\section{A B S T R A C T}

Mobile telecommunication operators routinely charge subscribers lower prices for calls on their own network than for calls to other networks (on-net discounts). Studies on tariffmediated network effects suggest this is due to large operators using on-net discounts to damage smaller rivals. Alternatively, research on strategic discounting suggests small operators use on-net discounts to advertise with low on-net prices. We test the relative strength of these effects using data on tariff setting in German mobile telecommunications between 2001 and 2009. We find that large operators are more likely to offer tariffs with onnet discounts but there is no consistently significant difference in the magnitude of discounts. Our results suggest that tariff-mediated network effects are the main cause of on-net discounts.

Keywords: Competition; Network effects; Mobile telecommunications; Pricing strategies JEL: D22, L11, L96

We are grateful to the editors Pai-Ling Yin and Tobias Kretschmer and two anonymous referees for constructive comments that helped improve the paper. For further insightful comments and suggestions, we are indebted to audiences at the $3^{\text {rd }}$ Workshop on the Economics of ICT in Porto, the ME-ICT Conference Munich, and the TIME Colloquium at the University of Munich. Marc Bourreau, Christoph Dehne, David Sauer, and Lior Zalmanson deserve special thanks for their insightful comments. The authors also gratefully acknowledge financial support for the data from the Deutsche Telekom Foundation.

\footnotetext{
${ }^{1}$ Corresponding author: Institute for Strategy, Technology and Organization, LMU Munich, Schackstrasse 4, 80539 Munich, Germany; Tel: +49 892180 6192; Fax: +49 89218016541

E-mail addresses: jcl.ino@cbs.dk (J. Claussen), 1.zucchini@1mu.de (L. Zucchini)
} 


\section{Introduction}

"The Autorité de la concurrence [French competition authority] fines Orange and SFR a total of $€ 183$ million for implementing anticompetitive practices in the mobile telephony sector. [Orange and SFR marketed tariffs with] abusive rate differentiation between 'on net' calls (within their respective networks) and 'off net' calls (to rival networks)."

(Autorité de la concurrence, 2012)

In this recent case two large mobile network operators in France were handed down a large fine for charging a lower minute price for calls to subscribers on their own network (onnet) than for calls to subscribers on other networks (off-net). This practice of granting "on-net discounts" is common in mobile telecommunication markets; it lowers the compatibility between mobile operators' networks, creating so-called tariff-mediated network effects (Laffont et al., 1998). Since telecommunication markets are subject to network effects, compatibility is important for market structures and profitability (Doganoglu and Grzybowski, 2007; Katz and Shapiro, 1994). Therefore, it is important for both scholars and regulators to understand which firms offer on-net discounts and why.

In the French case, the regulatory authority judged that the on-net discounts offered by Orange and SFR harmed competition by locking in customers to large networks and weakening a third competitor, Bouygues Télécom (Autorité de la concurrence, 2012). This conclusion is supported by theoretical research suggesting that large network operators use on-net discounts to leverage their installed bases and force small operators out of the market or prevent them from entering (Hoernig, 2007; Laffont et al., 1998). If this is the main motivation for on-net discounts, then we would expect to see them offered primarily by large operators and regulatory authorities should consider strict regulation.

However, recent research on marketing and consumer behavior suggests that on-net discounts may be used primarily as a marketing tool by small operators. The reason is that onnet discounts allow small operators to engage in strategic discounting, i.e. to attract customers by advertising low on-net prices while recouping profits with high off-net prices (Haucap and Heimeshoff, 2011; Lambrecht and Skiera, 2006). This strategy would be costly for large operators to imitate due to the high opportunity cost of setting low on-net prices with a large installed base. If this is the main motivation for on-net discounts, we would expect to observe them being offered predominantly by small operators. In that case regulating on-net discounts might harm competition by depriving small operators of an important marketing tool. 
The example from France and a similar case in Germany (German Federal Cartel Office, 2009) demonstrate that on-net discounts are an important issue. However, to be able to give sound policy advice we first need to understand the relative importance of these two effects. To our knowledge this has not yet been empirically investigated, i.e. we do not know whether on-net discounts are used predominantly by small or by large operators. We address this gap by analyzing two related questions: First, are large or small operators more likely to offer tariffs with on-net discounts, and second do they offer larger discounts? We do so using data on tariff setting in the market for German mobile telecommunications from 2001 to 2009. This market setting allows us to clearly differentiate between two groups of competitors, large mobile network operators (MNOs) and much smaller mobile virtual network operators (MVNOs), and also between MNOs of different size.

We test whether these groups differ in their tariff setting policies and find that large operators are more likely to offer tariffs with on-net discounts. On the other hand, we find that small operators appear to offer larger discounts, although this effect is not stable across all specifications. Our findings suggest that tariff-mediated network effects are the dominant mechanism responsible for on-net discounts. We conduct several robustness tests to ensure the observed effects are indeed due to network size and not to other unobserved differences.

Our study is the first to directly test whether large or small operators are more likely to offer tariffs with on-net discounts or offer larger discounts. This allows us to draw conclusions about the probable mechanisms causing operators to set on-net price discounts, contributing to research on competition in the telecommunication industry, and network markets in general. We also contribute to the policy discussion by offering tentative evidence that regulators may be correct to impose limits on on-net price differentials. In addition, sizeconditional regulation may be an interesting regulatory alternative to explore.

\section{Reasons for On-Net Discounts}

\subsection{Tariff-Mediated Network Effects}

Telecommunications is a standard example for an industry with direct network effects and a considerable body of research has investigated how they affect competitive behavior and welfare (Katz and Shapiro, 1994; Koski and Kretschmer, 2004). Generally, telecommunication operators charge consumers for their services using non-linear tariffs that comprise several price components like monthly fixed fees, minute prices per call, prices per 
text message, etc. Some of these tariffs have a lower per-minute price for calls to subscribers on the same network than for calls to subscribers on different networks.

There has been considerable concern among theoretical scholars of network industries that on-net discounts may be used to create "tariff-mediated network effects" (Laffont et al., 1998), with some studies even calling for regulation (Cabral, 2011; Gerpott, 2008; Harbord and Pagnozzi, 2010; Hoernig, 2008). Theoretical work has demonstrated that in markets with asymmetric players, large operators have an incentive to use on-net discounts as an anticompetitive instrument to damage smaller rivals (Berger, 2004; Jeon et al., 2004). By charging higher prices for off-net than for on-net calls, large operators can reduce the number and duration of calls received on the smaller operators' networks, making them less attractive to potential subscribers (Cabral, 2011; Hoernig, 2007). Large operators may also use on-net discounts to forestall entry by making new operators (with small installed bases) less attractive to consumers and consequently making entry less attractive (Calzada and Valletti, 2008).

In contrast to these arguments, several empirical papers postulate that it is not primarily global but rather local network effects that influence consumers' purchase decisions. The idea is that subscribers' utility is not equally increased by every new subscriber joining the network, but rather by the decisions of a small subset like friends and family, also known as "calling clubs" (Birke and Swann, 2010; Corrocher and Zirulia, 2009; Gabrielsen and Vagstad, 2008). This might make on-net discounts less attractive for large operators than in a situation with global network effects because consumers in the same calling club tend to cluster on networks in any case, so high on-net discounts of large operators would not deter entry by small operators.

However, a number of empirical studies provide evidence for global network effects in telecommunication markets. In addition to studies that infer network effects from a positive correlation between the size of an operator's installed base and its sales (Doganoglu and Grzybowski, 2007), there are several others that directly analyze the influence of network effects on consumers' choices in various markets. They generally concur that network effects are important for consumer behavior (Birke and Swann, 2006; Fu, 2004; Kim and Kwon, 2003).

In summary, research on tariff-mediated network effects suggests that large network operators use on-net discounts as an anti-competitive instrument and that this is important for consumers' choices. If tariff-mediated network effects are the dominant mechanism causing on-net discounts we would expect to observe larger operators being more likely to offer tariffs 
with on-net discounts and offering larger discounts than their smaller rivals. This is consistent with anecdotal evidence that on-net discounts were used as an anti-competitive instrument by the incumbent Vodafone in New Zealand (Haucap and Heimeshoff, 2011).

The introductory example suggests regulators have an interest in preserving competition in the market by protecting small operators and potential entrants from anti-competitive behavior by large operators. If we find that on-net discounts are predominantly used as an anticompetitive instrument, this would imply regulators should try to discourage or suppress them. They could do so by capping discounts - similar to recent regulation of roaming fees by the European Commission - or by banning them outright. An additional alternative would be to introduce size-dependent regulation, for example by linking a cap for on-net discounts to operators' market share.

An issue closely related to on-net discounts are termination fees (or access prices), fees charged by operators to other operators for connecting incoming calls to their subscribers. They affect on-net discounts in that they influence firms' marginal cost for off-net calls. A number of studies have demonstrated that if termination prices are a strategic variable, large operators have an incentive to raise them to damage smaller rivals - possibly even collusively - in the process raising on-net discounts (Berger, 2005; Cambini and Valletti, 2003; Gans and King, 2001; Genakos and Valletti, 2011; Harbord and Pagnozzi, 2010; Hoernig, 2007). Thus, when termination fees can be set strategically, the potential problems of anti-competitive behavior by large operators are exacerbated. In our empirical setting, termination fees are strictly regulated by the national regulator and are not a strategic variable for the operators.

\subsection{Strategic Discounting}

In contrast to the clear prediction from research on tariff-mediated network effects there is anecdotal evidence from several European mobile telecommunication markets that small operators were the first to introduce on-net discounts (Haucap and Heimeshoff, 2011; Haucap et al., 2011). This is surprising given the results cited above as it suggests small operators may have stronger incentives to introduce on-net discounts than their larger rivals.

One explanation is that consumers' evaluation of mobile tariff options is not completely rational. Recent studies have found that consumers are bad at estimating the proportion of their future on-net and off-net calls, causing them to exhibit an excess preference for flat-rate tariffs (Lambrecht et al., 2007; Lambrecht and Skiera, 2006). It also causes them to overestimate the savings from a particularly low on-net or off-net price, a phenomenon Haucap and Heimeshoff (2011) call a "price differentiation bias". 
Haucap and Heimeshoff (2011) argue that because of the price differentiation bias small operators can attract consumers by advertising with low on-net prices while still making profits with off-net calls. This strategy is feasible because they have a large proportion of offnet calls due to their relatively small installed base. It is costly for large operators to imitate because they have a larger proportion of on-net calls due to their larger installed base.

At first glance this line of argument may seem to contradict what one would expect in a network market: in those markets, firms with large installed bases normally prefer low compatibility while firms with small installed bases prefer high compatibility (Besen and Farrell, 1994). One reason this strategy may be feasible nevertheless is local network effects, which we described above. If local network effects are more important than global network effects, a strategic discounting strategy may be feasible because groups of consumers cluster on networks, reducing the importance of compatibility on a global scale. On the other hand, local network effects may also reduce the attractiveness of strategic discounting for small operators: if most of consumers' calls are placed on their own network then small operators' opportunity to recoup profits with off-net calls is reduced. We are unable to estimate the relative importance of these two mechanisms; further research in this area would be interesting.

Together, these results provide an explanation for why on-net discounts may be attractive for small telecommunication operators. They suggest we should observe small operators offering on-net discounts. If this is the case, regulators should carefully consider whether regulating on-net discounts might be harmful to small operators and by extension to competition.

Note that the two alternative explanations for on-net discounts - tariff-mediated network effects and strategic discounting - are not necessarily mutually exclusive. It is possible that they are both correct to a degree and cancel out, in which case we would not observe a clear preference for on-net discounts either by small or large operators. It is also conceivable that both of them are wrong, although this seems unlikely given the body of supporting evidence for each theory.

\section{Empirical Setting}

The empirical setting for our study is the German market for mobile telecommunications between 2001 and 2009. This section provides a brief overview of the market. 


\subsection{Technical Standards and Market Growth}

Two technical standards provided the basis for mobile telecommunications in Germany during the period covered by our dataset: The GSM standard (Global System for Mobile Communications) had been in use since 1993. In addition, in 2004 networks operating on the UMTS (Universal Mobile Telecommunication System) standard were activated, after which all competitors in the market operated on both standards in parallel.

During the period under observation the market for mobile telephony in Germany grew rapidly. This development had begun in the mid-1990s and started to slow down towards the end of our observation period. For example, between 2001 and 2009 the penetration rate (subscriptions divided by total population) almost doubled from $68 \%$ to $132 \%$ (German Federal Network Agency, 2010). Total usage also increased strongly with outgoing calls from mobile networks tripling from 31 bn. minutes in 2001 to 94 bn. minutes in 2009 (German Federal Network Agency, 2005, 2010).

\subsection{Operators}

Three types of companies are active in the German mobile telecommunication market. First, there are four large mobile network operators (MNOs) that entered the market prior to 1995 and jointly held well over 80\% market share (T-Mobile, Vodafone, E-Plus and O2). Of the four MNOs, T-Mobile and Vodafone were substantially larger than the other two: In 2004 they had approximately 27 million subscribers each while E-Plus and $\mathrm{O} 2$ had only 9.5 and 7.4 million subscribers, respectively (Merrill Lynch Global Wireless Matrix). Although the smaller operators gained some ground during the period under observation, the market shares remained fairly stable. They also have similar business models: they are all vertically integrated companies targeting a mass market from rare callers to heavy business users. They all sell tariffs and operate extensive retail chains, and also own and operate infrastructure for telecommunication services including masts, switches, backbones, and bandwidth licenses.

The second group of companies comprises 67 mobile virtual network operators (MVNOs, e.g. SVEN or AldiMobil), the first of whom entered the market beginning in late 2004 and early 2005. Since then they rapidly gained ground but during the period covered by this study they held a joint market share of below $20 \%$, meaning they were an order of magnitude smaller than the MNOs (German Federal Network Agency, 2009). In contrast to the MNOs they do not own or operate their own infrastructure. Instead, they buy airtime wholesale from the MNOs and use it to construct new tariffs that are sold under their own brand. MVNOs generally focus on low-usage market segments and some of them are subsidiary brands of MNOs specifically targeting those segments (e.g. Congstar or Simyo). 
The final group of companies in the market is made up of 23 tariff resellers (e.g. Mobilcom or Freenet). Most of these companies operate extensive branch networks in Germany from which they sell MNO tariffs. In contrast to MNOs and MVNOs, tariff resellers generally do not actually provide mobile telecommunication services, i.e. they do not structure and sell tariffs under their own brand. Instead, they operate as an independent distribution platform for MNO tariffs and the vast majority of their offering comprises MNO tariffs sold under a joint brand. They were excluded from the analysis in this study as including them would have artificially inflated the number of tariffs in the market.

\subsection{Regulation}

The market is subject to regulation by the German Federal Network Agency (Bundesnetzagentur). Most importantly, MNOs are required to ensure interoperability between their networks. When receiving a call from another network that terminates on their own network they may charge a termination fee. The termination fees are strictly regulated by the Federal Network Agency based on an estimation of the different competitors' marginal costs. The maximum permissible termination fees during the period covered by our dataset are given in Table 1. Two patterns are striking there: First, the two smaller MNOs were allowed to charge higher termination fees than the larger ones due to their higher marginal costs (lower market share and hence lower economies of scale) and second, overall termination fees were reduced over time. Termination fees are closely linked to on-net discounts and we discuss below how they are taken into account in the econometric analyses. Note that MVNO tariffs always operate on one of the MNOs' networks. They are therefore subject to the same set of termination fees as the MNO whose infrastructure they use.

\section{INSERT TABLE 1 HERE}

\subsection{Tariffs with On-net Discounts}

Figure 1 illustrates how the number of tariffs introduced in the market grew between 2001 and 2008. It shows the number of newly introduced tariffs by MNOs and MVNOs (light and dark bars, respectively). Note the entry of the MVNOs in late 2004 and the subsequent rise in the MVNOs' proportion of newly introduced tariffs. The figure also shows the proportion of new tariffs with on-net discounts. Two developments are notable: In the early 2000s a majority of MNO tariffs had on-net discounts (74\% in 2001) but this proportion decreased to 
$43 \%$ by 2008 . Second, approximately $20 \%$ of newly introduced MVNO tariffs had on-net discounts - substantially less than the MNOs.

\section{INSERT FIGURE 1 HERE}

In an investigation by the German Federal Cartel Office (German Federal Cartel Office, 2009) E-Plus, one of the smaller MNOs, registered a complaint in 2007 against the two larger MNOs for misusing on-net discounts to cement their position as market leaders. In 2009 the Cartel Office dropped the case, arguing that on-net discounts no longer played a major role in the German mobile telecommunication market. This is consistent with the decreasing trend in the proportion of new tariffs with on-net discounts in our dataset, but seems somewhat surprising given the still relatively large proportion in 2008.

This decrease in the proportion of tariffs with on-net discounts could have several reasons. It could be due to the increasing importance of flat-rate tariffs or the regulated decrease in termination fees discussed above (German Federal Cartel Office, 2009). An alternative explanation is that increasing saturation in the market caused the number of new subscribers to decrease for all operators. This could mean that on-net discounts become less attractive for operators because their effect is reduced - there are simply less new subscribers to attract with them. We leave a detailed investigation of these questions to future research, noting only that despite the fact that they lost some of their importance in Germany, on-net discounts were a common instrument during the period covered by our dataset. They also remain a pervasive phenomenon in telecommunication markets in general.

\section{Data and Estimation}

\subsection{Data}

We observe tariffs introduced to the German market for mobile telecommunications from $1 / 2001$ to $2 / 2009$. The data were gathered by teltarif.de, a price comparison website tracking all mobile tariffs in the German market, and was subjected to extensive cleaning. The most important steps of the data cleaning process are described in the Appendix B. Our observations for most models are at the tariff-level, i.e. each observation corresponds to a new tariff in the month it was first introduced. For each tariff we can uniquely identify the operator offering it, whether or not it had an on-net price discount, and how large the discount was. 
Data on the MNOs' market shares were taken from the Merrill Lynch Global Wireless Matrix, a report on the development of the global mobile telephony markets published on a quarterly basis by the US investment bank Merrill Lynch. Data on market shares of the MVNOs were not available.

\subsection{Empirical Strategy}

Our first empirical question is whether larger operators are more likely to offer tariffs with an on-net discount. We therefore estimate the probability that any given tariff has an on-net discount, i.e. that the off-net minute price is larger than the on-net minute price. To do so we estimate a logit model with standard errors clustered at the level of the firm.

Our second empirical question is whether larger operators offer larger on-net discounts. For this question we restrict the sample to only tariffs with a non-zero on-net discount and measure the relative difference between on-net and off-net minute prices. This can be interpreted as the discount in percent that is granted subscribers for placing calls on their own operator's network rather than calling consumers on other networks. We use OLS models for these estimations, again clustering standard errors at the level of the firm.

Our main independent variable is operator size. As described above the operators in the market fall naturally into two categories. The MNOs are larger than the MVNOs by an order of magnitude, allowing us to clearly identify large and small operators in the market. We use a dummy for each operator's type as a proxy for its size and compare the differences in tariff setting between the MNOs and the MVNOs. This allows us to include all the operators in the market despite the fact that size data like the number of subscribers or revenues were unavailable for the MVNOs.

Although the MNO dummy demarcates a clear difference in operator size it is also perfectly correlated with a difference in business model between MNOs and MVNOs. Whereas the large MNOs own and operate expensive physical network infrastructures, the MVNOs operate as wholesalers. Therefore differences in tariff setting due to the business models might appear as size effects, creating spurious results. To ensure that this is not the case, we conduct robustness tests that exploit the variation in size between the two large and the two small MNOs. These two groups share the same business model, so by comparing differences in tariff setting between them we can clearly identify the influence of size on tariff setting. For these models we use separate dummy variables to uniquely identify firms in each of the two groups. 


\subsection{Variables}

We introduce the main variables used in the regressions below. Descriptive statistics and pairwise correlations for the dependent, independent and main control variables are reported in Tables 2 and 3, respectively (the year dummies are omitted). The correlations between the independent variables are all quite low.

\section{INSERT TABLES 2 AND 3 HERE}

\section{Discount Given}

Our first dependent variable is the probability that a given tariff has an on-net discount. We measure this using the dummy variable Discount Given which is coded 1 for each of the 744 tariffs where the off-net minute price is higher than the on-net minute price, and 0 for the other 718. Note that for all tariffs with a difference between on-net and off-net prices, the offnet prices are always higher.

\section{Discount Size}

Our second empirical question is whether larger operators offer larger on-net discounts. For this question we restrict the sample to tariffs offering an on-net discount. We measure the difference using the variable Discount Size $=\left(p_{\text {on }}-p_{\text {off }}\right) / p_{\text {off }}$, where $p_{\text {on }}$ and $p_{\text {off }}$ are the minute prices in (euro) cents for on- and off-net calls, respectively. We observe a number of tariffs where $p_{\text {off }}=0$ but in all of these cases $p_{\text {on }}=0$ as well, so the tariffs are not in the choice set because the price differential was zero.

$M N O$, Small MNO, and Large MNO

As described above, operator size is proxied by a dummy variable: $M N O$ is coded 1 if a tariff is offered by an MNO and 0 otherwise. In addition, we test our results using the variation in size between the two large and small MNOs. This is measured with the dummy variables Small MNO (1 for E-Plus and O2) and Large MNO (1 for T-Mobile or Vodafone).

\section{Market and Year Fixed-Effects}

To control for the fact that MNOs and MVNOs emphasize different market segments, we include Market Fixed-Effects in the regression models. To do so, we allocate each tariff to one of four market segments: rare, low, average and heavy users. The allocation was performed with a standardized algorithm, checked by hand, and subjected to extensive robustness tests. The procedure is described in the appendix. Dummies are used for the low, average, and heavy usage markets with the rare users as the base category. 
We also include Year Fixed-Effects dummy variables to control for changes over time like regulatory changes.

\section{Termination Fees}

Finally, we include the variable Termination Fees to address the concern that our results may be influenced by the different levels of termination fees for different operators at any given time as depicted in Table 1. If large MNOs have to pay higher termination fees it seems plausible that they would charge higher prices for off-net calls than small MNOs and therefore have larger on-net discounts. This would be observationally similar to large operators setting larger on-net discounts to induce tariff-mediated network effects. In principle this should not strongly influence our main regressions, because here we compare MNOs and MVNOs, not large and small MNOs. Therefore the difference in termination prices between large and small operators should only matter if MVNO tariffs are systematically more likely to operate on small (or large) MNOs' networks. Nevertheless, this is an important concern and we control for termination fees in all models.

To control for the effect of termination fees we need to measure an average termination fee for each tariff. We therefore construct a control variable as follows: The 'incoming' termination prices in Table 1 are interpolated to financial quarters and weighted with quarterly market shares for the four physical networks (T-Mobile, Vodafone, E-Plus and O2) using data from the Merrill Lynch Global Wireless Matrix. We assume that mobile phone usage roughly reflects network size and calculate an average termination fee for each tariff as the weighted average of termination prices to the three networks other than the one on which the tariff operates. This measures what each tariff costs the operator in terms of outgoing termination fees.

\section{Results}

\subsection{Descriptive Results}

Table 4 shows descriptive statistics for the 1,462 tariffs in our final dataset. The first column shows the number of tariffs offered by the larger and smaller MNOs (T-Mobile and Vodafone, and E-Plus and O2, respectively) and the MVNOs. The second and third columns give the absolute and relative number of tariffs with an on-net discount. At first glance the data in the third column strongly suggest a positive correlation between the relative number of tariffs with on-net discounts and operator size: Only 14\% of MVNO tariffs have on-net discounts, for small MNOs it is $48 \%$, and for large MNOs it is $75 \%$. Apparently, larger 
operators are more likely to offer tariffs with on-net discounts, suggesting our data support tariff-mediated network effects as the central driver of on-net discounts.

\section{INSERT TABLE 4 HERE}

For the 744 tariffs that had on-net discounts, the fourth column in Table 4 shows the average magnitude of the relative discount, i.e. the difference between the off-net and on-net minute prices divided by the on-net minute price. These numbers are also suggestive, but in exactly the opposite direction than the probability of discounts: For tariffs with on-net discounts, MVNOs offer an average discount of $80 \%$, for small MNOs it is $55 \%$ and for large MNOs only $49 \%$. This seems to suggest that smaller operators use larger on-net discounts, supporting the argument that strategic discounting is the mechanism causing on-net discounts for smaller operators. It also seems plausible that the on-net discounts should be larger for small operators if they are using them as a strategic marketing tool: in that case they would want to exploit the "price differentiation bias" cited above by making the on-net prices noticeably low, which would cause large on-net discounts.

\subsection{Main Results}

MNOs vs. MVNOs

Table 5 reports the results of our main regression models. Model (5-1) shows the results (average marginal effects) of the logit regression estimating the probability of a tariff having an on-net discount depending on whether it is offered by an MNO or an MVNO. The marginal effect of the MNO dummy is highly significant and large: Tariffs offered by MNOs are more than $26 \%$ more likely to have an on-net discount than those offered by MVNOs. This is consistent with the descriptive results in Table 4 and supports the prediction that tariffmediated network effects are the main cause of on-net differentials.

\section{INSERT TABLE 5 HERE}

Model (5-4) pertains to our second empirical question, reporting coefficients and standard errors (in parentheses) for the OLS regressions estimating the magnitude of on-net discounts for the 744 tariffs that had a non-zero discount. The OLS model also bears out the descriptive results in Table 4: The coefficient for the MNO dummy is significantly negative, indicating 
that smaller operators offered larger on-net discounts. Apart from being statistically significant the effect is also large in economic terms: small operators offer on-net discounts that are around 17 percentage-points larger than their larger rivals. However, while this result suggests that strategic discounting may be the cause of on-net discounts it is not consistently significant in the other models reported below and we must therefore interpret it with caution.

Taken together, the results in column (5-1) and (5-4) indicate that whereas large operators are more likely to offer discounts, small operators offer larger discounts.

\section{Currently Offered Instead of New Tariffs}

We focus on newly introduced tariffs because we believe the relevant economic decision of determining the on-net discounts is made at the time of the tariff launch. However, if tariffs with different on-net discounts are not offered for the same length of time this could distort our results. To rule out this possibility, we run another set of regressions in which we include one tariff-quarter observation for each tariff currently offered in each quarter. As this artificially inflates the number of observations and tariffs do not change over time, we cluster the standard errors at the tariff level. In column (5-2) and (5-5) we reproduce the results from columns (5-1) and (5-4), using the new data structure of currently offered instead of new tariffs. Our results for the MNO dummy are extremely stable both in magnitude and significance, making it unlikely that tariffs being on the market for different lengths of time influence our results.

\section{Small vs. Large MNOs}

A possible alternative explanation for our results is that the MNO dummy used as a proxy for size is perfectly correlated with a difference in business models between operators. As described above, the MNOs are not only much larger than the MVNOs but also vertically integrated, each owning and managing its own network infrastructure. By contrast, the MVNOs don't own or operate network infrastructure, rather buying airtime wholesale from the MNOs and repackaging it to tariffs. This could mean our results are due to a difference in business model rather than operator size, casting doubt on our conclusions about the causes of on-net discounts.

To explore this alternative explanation we exploit the variation in size between the two larger and the two smaller MNOs. In model (5-3) we re-estimate model (5-1), splitting the MNO dummy into dummies for small and for large MNOs. This allows us to rule out the effect of business models: although the larger and smaller MNOs differ substantially in size they all share the same business model. Comparing models (5-1) and (5-3) we see that the effects 
seem to be mainly due to difference between large MNOs and other firms, implying that our results are not due to differences in business model.In model (5-6) we do the same thing for the OLS models estimating the magnitude of on-net discounts with similar results. It is notable that in these tests the marginal effects of the MNO and Large MNO dummies are not only identical in sign and significance but also of very similar magnitude, ranging between 0.260 and 0.375 (Models 5-1 and 5-3) for the logit models and between -0.151 and -0.169 (Models 6-5 and 5-4).

\subsection{Robustness Tests}

\section{Tariff Components}

A potential problem could be that our Market Fixed-Effects imperfectly capture the effect of different market segments. If tariffs are aimed at different types of consumers and the type of tariff offered varies systematically with operator size, this might need more careful treatment. We therefore re-estimate models (5-1) and (5-4) including the control variables Contract Duration, Free Minutes, and Base Fee.

Minimum contract duration of a tariff could serve as an alternative mechanism to increasing switching costs, possibly altering on-net discounts. For the tariffs offering free minutes, subscribers are allotted a certain contingent of calling minutes whose price is bundled with the monthly base fee. With a higher fixed fee and a lower minute price these tariffs are targeted at subscribers with heavier usage. The variable Base Fee captures the other end of the spectrum: Tariffs that do not contain a base fee have ceteris paribus higher minute prices, indicating that these tariffs are offered to subscribers with particularly low usage.

Models including these control variables are reported in columns (6-1) and (6-4) of Table 6. The result of the logit regression stays qualitatively unchanged compared to model (5-1), but the OLS regression loses significance compared to model (5-4). Note that Contract Duration, Free Minutes, and Base Fee are tariff components and are therefore set simultaneously with the on-net discounts. That makes them highly endogenous to on-net discounts, which is why they are only used to check the robustness of our main results.

\section{INSERT TABLE 6 HERE}

\section{Market Shares}

Our results might also be influenced by the use of dummies as proxies for operator size. In regressions reported in column (6-2) and (6-5) of Table 6, we therefore use operators' Market 
Share as the main independent variable. Note that as data on market shares for MVNOs were unavailable, we reduce the sample to only MNOs for these models. The marginal effect for market share on the probability and size of the discount is not significant, which might indicate a problem with the size dummy. However, market share is highly collinear with the termination fees and years by construction, since the termination fees were set by the regulator using operators' market shares and reduced over time (see Table 1).

In the model of the probability of a discount (6-2) the marginal effect of size is of a similar order of magnitude to the other models, but including both market share, year dummies and termination fees leads to a strongly inflated standard error. For instance, not including the year dummies in specification in (6-2) increases the significance of the Market Share variable above a $99 \%$ level (results not reported in paper), but leaves estimate of the marginal effects almost unchanged. We are therefore confident that the lack of significant results in the probability model is due to the collinearity between market share and termination fees and not to a misspecification in the model.

For the model of the discount size (6-5) there is a similar multicollinearity problem, but here not only does the standard error of the estimated marginal effect increase dramatically, but the estimate drops to almost zero. We are therefore more cautious in our interpretation of this result, especially since it is also not robust in the other tests.

\section{Reduced Sample}

Finally, the year fixed-effects may imperfectly capture the effect that MVNOs only started entering the market from late 2004. To test for this, we run models (5-1) and (5-4) using only data from 2005 to 2009. The results are reported in the columns (6-3) and (6-6) of Table 6. In the logit model the MNO marginal effect is smaller but is still significant, whereas the MNO marginal effect in the OLS model is no longer significantly different from zero.

\section{Discussion, Limitations, and Conclusion}

\subsection{Discussion}

We set out to investigate whether tariff-mediated network effects or strategic discounting are the dominant motivation behind on-net discounts in mobile telecommunication tariffs. To do so we used data from the German mobile telecommunication market between 2001 and 2009 and analyzed two related questions: are large operators more likely to offer tariffs with on-net discounts, and do they offer larger on-net discounts. Initial results (Tables 4 and 5) suggest that both explanations may be accurate: larger operators are more likely to offer 
tariffs with on-net discounts, but smaller operators appear to offer larger on-net discounts. We conducted a number of robustness tests to rule out alternative explanations. The first result is essentially stable across all these tests. Although in models testing for differences between all three groups of operators only the difference between large MNOs and other firms is significant, even there the basic effect is visible: larger operators are more likely to offer tariffs with on-net price discounts. The second initial result is not robust to different model specifications and samples. In models with the magnitude of on-net discounts as the dependent variable, the coefficients for operator size variables are consistently negative but only significant in the models in Table 5. We conclude that although there are some indications small operators may offer larger on-net discounts our data do not allow us to draw strong conclusions.

In sum, our results are consistent with theoretical models that propose tariff-mediated network effects are the main driver of on-net discounts. By contrast, despite some indications that small operators may offer larger on-net discounts, our findings do not offer consistent support for strategic discounting as an explanation for on-net discounts in mobile telecommunications. As discussed previously the two explanations imply opposite effects and may cancel out. This strengthens our findings regarding the positive effect of operator size on the probability of a tariff having an on-net discount. It also offers one interpretation of the lack of findings concerning the effect of operator size on the magnitude of discounts, but since we only observe a net effect this is speculative.

Our results may be of interest to regulators. There has been considerable concern that large operators use on-net discounts as an anti-competitive instrument and in the French case cited above two large operators were forced to pay hefty fines for the practice. We cautiously interpret the results presented here as supporting the regulation of on-net discounts by large operators. This would enable small operators to continue to use them as a marketing instrument but limit their use as an anti-competitive instrument by large operators. However, these policy implications should be treated with caution, as they stretch what we can reliably infer from the data.

\subsection{Limitations}

Despite several robustness tests our study has limitations. First, we do not observe the causal mechanisms proposed by previous theoretical work directly but only behavioral patterns consistent with them. Future work directly measuring these effects might provide a more detailed picture of the motivations for termination-based price discrimination. 
Second, we do not observe the number of consumers purchasing each tariff. This means we make an implicit assumption that operators only offer tariffs that actually attract subscribers. We find this fairly uncontroversial but nevertheless data on sales would allow us to directly study the link between termination-based price discrimination, consumer choices, and profitability. It would also allow us to gain a more comprehensive understanding of the interaction between operators' installed bases and their competitive behavior.

Third, we limit our analysis to mobile telecommunications and exclude fixed-line or other telecommunication services. During the period of observation, the two large MNOs offered fixed-line and broadband services in addition to mobile telecommunication plans. This provided them with an additional instrument to increase consumers' switching costs. The other operators in the market did not have similar additional competitive instruments to create lock-in effects. If anything, firms that can use bundling and cross-selling effects to lock in customers should find (costly) on-net discounts ceteris paribus less attractive. However, our results suggest that on-net discounts are predominantly used by the very companies who had these additional instruments at their disposal: the large MNOs. While this further strengthens our confidence in the empirical results, it nevertheless remains an interesting line of enquiry: simultaneous studies of the interdependencies between fixed-line, mobile, and broadband markets may provide more comprehensive insights into competition through tariff-mediated network effects (Pereira and Ribeiro, 2011; Pereira et al., 2011).

Finally, our data are limited to a turbulent period in the mobile telecommunication industry in Germany. A cross-validation of our results in other market settings would be beneficial.

\subsection{Conclusion}

On-net discounts are a pervasive phenomenon in telecommunication markets. Although there is widespread agreement that they are used as a competitive instrument, there are two different explanations for why. On the one hand, research on tariff-mediated network effects posits that large operators use on-net discounts to leverage their installed base and decrease the attractiveness of smaller rivals (Laffont et al., 1998). This theory predicts that on-net discounts should be offered primarily by larger operators. On the other hand, recent work on strategic discounting suggests that on-net discounts are used by small operators: they advertise with low on-net prices to attract subscribers while keeping off-net prices high to ensure profitability (Haucap and Heimeshoff, 2011). This strategy is costly for their larger rivals to imitate as low on-net prices would cause them much greater opportunity costs due to 
their larger networks. This theory implies that on-net discounts should be offered primarily by smaller operators.

Our empirical results show that large operators are more likely to offer tariffs with on-net discounts. We cautiously interpret this as suggesting that large operators using tariff-mediated network effects as a competitive instrument are the dominant reason for on-net price differentials.

Our study contributes to research on competition in network industries. In particular, we provide the first empirical test of two alternative theories explaining the phenomenon of onnet price discounts in telecommunication markets. We show that large firms may indeed strategically use tariff-mediated network effects and draw tentative conclusions for regulators. 


\section{References}

Autorité de la concurrence RF 2012. Press Release 13.12.2012: Mobile telephony. vol. 2013. République Francaise - Autorité de la concurrence.

Berger U. Access Charges in the Presence of Call Externalities. The B.E. Journal of Economic Analysis \& Policy 2004;3.

Berger U. Bill-and-Keep vs. Cost-based Access Pricing Revisited. Economics Letters 2005;86; 107-112.

Besen SM, Farrell J. Choosing how to compete: Strategies and tactics in standardization. The Journal of Economic Perspectives 1994;8; 117-131.

Birke D, Swann G. Network effects and the choice of mobile phone operator. Journal of Evolutionary Economics 2006;16; 65-84.

Birke D, Swann GMP. Network Effects, Network Structure and Consumer Interaction in Mobile Telecommunications in Europe and Asia. Journal of Economic Behavior \& Organization 2010;76; 153-167.

Cabral L. Dynamic Price Competition with Network Effects. The Review of Economic Studies 2011;78; 83-111.

Calzada J, Valletti TM. Network Competition and Entry Deterrence*. The Economic Journal 2008;118; 1223-1244.

Cambini C, Valletti TM. Network competition with price discrimination: 'bill-and-keep' is not so bad after all. Economics Letters 2003;81; 205-213.

Corrocher N, Zirulia L. Me and You and Everyone We Know: An Empirical Analysis of Local Network Effects in Mobile Communications. Telecommunications Policy 2009;33; 68-79.

Doganoglu T, Grzybowski L. Estimating Network Effects in Mobile Telephony in Germany. Information Economics and Policy 2007;19; 65-79.

$\mathrm{Fu}$ WW. Termination-Discriminatory Pricing, Subscriber Bandwagons, and Network Traffic Patterns: the Taiwanese Mobile Phone Market. Telecommunications Policy 2004;28; 522.

Gabrielsen TS, Vagstad S. Why is on-net traffic cheaper than off-net traffic? Access markup as a collusive device. European Economic Review 2008;52; 99-115.

Gans JS, King SP. Using 'bill and keep' Interconnect Arrangements to Soften Network Competition. Economics Letters 2001;71; 413-420.

Genakos C, Valletti T. Testing the "Waterbed" Effect in Mobile Telephony. Journal of the European Economic Association 2011;9; 1114-1142.

German Federal Cartel Office 2009. Prüfung eines möglichen Missbrauchs einer marktbeherrschenden Stellung durch günstigere On-Net-Tarife in der

Mobilfunksprachtelefonie durch T-Mobile und Vodafone. vol. B7 - 170/07.

German Federal Network Agency 2005. Jahresbericht 2005. Dresden.

German Federal Network Agency 2009. Jahresbericht 2009. Dresden.

German Federal Network Agency 2010. Jahresbericht 2010. Dresden.

German Federal Statistical Agency 2006. Recalculating the Consumer Price Index for Telecommunications Services on Base 2000.

Gerpott TJ. Termination-Discriminatory Pricing in European Mobile Telecommunications Markets. International Journal of Mobile Communications 2008;6; 564-586.

Harbord D, Pagnozzi M. Network-Based Price Discrimination and 'Bill-and-Keep' vs. 'CostBased' Regulation of Mobile Termination Rates. Review of Network Economics 2010;9; $1-43$.

Haucap J, Heimeshoff U. Consumer behavior towards on-net/off-net price differentiation. Telecommunications Policy 2011;35; 325-332. 
Haucap J, Heimeshoff U, Stühmeier T. Wettbewerb im Deutschen Mobilfunkmarkt. Zeitschrift für Wirtschaftspolitik 2011;60; 240-267.

Hoernig S. On-net and off-net pricing on asymmetric telecommunications networks. Information Economics and Policy 2007;19; 171-188.

Hoernig S. Tariff-Mediated Network Externalities: Is Regulatory Intervention Any Good? CEPR Discussion Paper 2008.

Jeon D-S, Laffont J-J, Tirole J. On the "Receiver-Pays" Principle. The RAND Journal of Economics 2004;35; 85-110.

Katz ML, Shapiro C. Systems Competition and Network Effects. The Journal of Economic Perspectives 1994;8; 93-115.

Kim H-S, Kwon N. The Advantage of Network Size in Acquiring New Subscribers: a Conditional Logit Analysis of the Korean Mobile Telephony Market. Information Economics and Policy 2003;15; 17-33.

Koski H, Kretschmer T. Survey on Competing in Network Industries: Firm Strategies, Market Outcomes, and Policy Implications. Journal of Industry, Competition and Trade 2004;4; $5-31$.

Kruse J. Mobilterminierung im Wettbewerb. Jahrbuch für Wirtschaftswissenschaften 2009;60; 1-16.

Laffont J-J, Rey P, Tirole J. Network Competition: II. Price Discrimination. The RAND Journal of Economics 1998;29; 38-56.

Lambrecht A, Seim K, Skiera B. Does Uncertainty Matter? Consumer Behaviour Under Three-Part Tariffs. Marketing Science 2007;26; 698-710.

Lambrecht A, Skiera B. Paying Too Much and Being Happy About It: Existence, Causes, and Consequences of Tariff-Choice Biases. Journal of Marketing Research 2006;43; 212223.

Pereira P, Ribeiro T. The impact on broadband access to the Internet of the dual ownership of telephone and cable networks. International Journal of Industrial Organization 2011;29; 283-293.

Pereira P, Ribeiro T, Vareda J 2011. Delineating Markets for Bundles with Consumer Level Data: The Case of Triple-Play. ICT and Economic Growth Conference Munich. Munich. 
Figures and Tables

Table 1: Development of Termination Fees in Germany (in cents)

\begin{tabular}{lccccccccc} 
& 2001 & 2002 & 2003 & 2004 & 2005 & 2006 & 2007 & 2008 & 2009 \\
\hline T-Mobile & 14.39 & 14.39 & 15.40 & 14.20 & 11.80 & 10.80 & 8.78 & 7.92 & 7.92 \\
Vodafone & 15.42 & 15.42 & 14.30 & 13.20 & 11.00 & 10.20 & 8.78 & 7.92 & 7.92 \\
E-Plus & 19.03 & 19.03 & 17.90 & 16.50 & 13.70 & 12.70 & 9.94 & 8.80 & 8.80 \\
O2 & 18.77 & 18.77 & 17.90 & 16.50 & 13.70 & 12.70 & 9.94 & 8.80 & 8.80 \\
\hline
\end{tabular}

Notes: Fee per minute in cents that each network could charge other networks for incoming calls, e.g. in 2001 T-Mobile was allowed to charge any of the others 14.39 cents/minute for calls terminating on its network. Source: Kruse (2009) 
Figure 1: New Tariffs and Proportion of Tariffs with On-Net Discount (2001-2008)

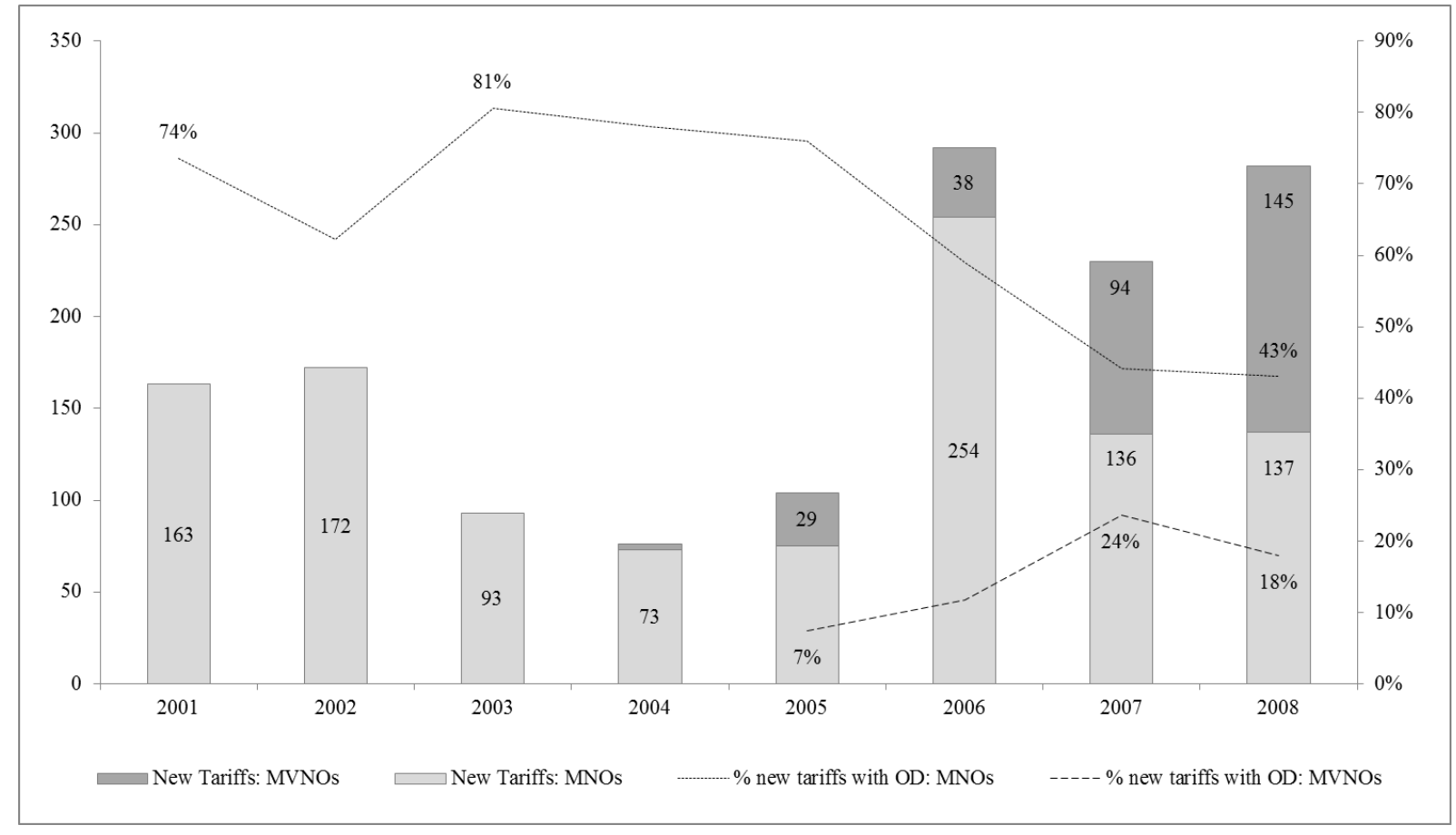

Source: Teltarif data 
Table 2: Descriptive Statistics

\begin{tabular}{|c|c|c|c|c|c|}
\hline Variable & Dummy & Mean & SD & Min & $\operatorname{Max}$ \\
\hline Discount Given & yes & 0.51 & 0.50 & 0 & 1 \\
\hline Discount Size & no & 0.28 & 0.31 & 0 & 1 \\
\hline MNO & yes & 0.78 & 0.42 & 0 & 1 \\
\hline Large MNO & yes & 0.39 & 0.49 & 0 & 1 \\
\hline Small MNO & yes & 0.39 & 0.49 & 0 & 1 \\
\hline Termination Fees & no & 11.72 & 2.98 & 8.06 & 16.63 \\
\hline Contract Duration & yes & 0.84 & 0.36 & 0 & 1 \\
\hline Base Fee & yes & 0.84 & 0.36 & 0 & 1 \\
\hline Free Minutes & yes & 0.27 & 0.45 & 0 & 1 \\
\hline Market: Low & yes & 0.25 & 0.44 & 0 & 1 \\
\hline Market: Average & yes & 0.24 & 0.43 & 0 & 1 \\
\hline Market: Heavy & yes & 0.35 & 0.48 & 0 & 1 \\
\hline
\end{tabular}


Table 3: Pairwise Correlations

\begin{tabular}{|c|c|c|c|c|c|c|c|c|c|c|c|c|c|}
\hline \multicolumn{2}{|c|}{ Variable } & (1) & $(2)$ & (3) & (4) & $(5)$ & (6) & $(7)$ & $(8)$ & (9) & (10) & (11) & (12) \\
\hline (1) & Discount Given & 1.00 & & & & & & & & & & & \\
\hline (2) & Discount Size & 0.86 & 1.00 & & & & & & & & & & \\
\hline (3) & MNO & 0.39 & 0.26 & 1.00 & & & & & & & & & \\
\hline (4) & Large MNO & 0.39 & 0.26 & 0.43 & 1.00 & & & & & & & & \\
\hline (5) & Small MNO & -0.05 & -0.04 & 0.43 & -0.63 & 1.00 & & & & & & & \\
\hline (6) & Termination Fees & 0.37 & 0.20 & 0.46 & 0.13 & 0.26 & 1.00 & & & & & & \\
\hline (7) & Contract Duration & 0.07 & 0.12 & 0.28 & -0.06 & 0.29 & -0.08 & 1.00 & & & & & \\
\hline (8) & Base Fee & 0.20 & 0.18 & 0.40 & 0.15 & 0.19 & 0.10 & 0.68 & 1.00 & & & & \\
\hline (9) & Free Minutes & -0.25 & -0.34 & 0.28 & 0.20 & 0.04 & -0.13 & 0.24 & 0.26 & 1.00 & & & \\
\hline (10) & Market: Low & 0.24 & 0.12 & 0.24 & 0.09 & 0.12 & 0.28 & 0.15 & 0.19 & -0.03 & 1.00 & & \\
\hline (11) & Market: Average & -0.05 & -0.12 & 0.02 & 0.05 & -0.03 & -0.11 & 0.14 & 0.16 & 0.18 & -0.32 & 1.00 & \\
\hline (12) & Market: Heavy & -0.06 & 0.13 & -0.02 & -0.06 & 0.04 & -0.20 & 0.27 & 0.31 & 0.06 & -0.41 & -0.41 & 1.00 \\
\hline
\end{tabular}


Table 4: Tariffs and On-net Discounts by Operator Type (2001-2009)

\begin{tabular}{lcccc} 
& Tariffs & $\begin{array}{c}\text { Tariffs with } \\
\text { discount }\end{array}$ & $\begin{array}{c}\text { \% with } \\
\text { discount }\end{array}$ & $\begin{array}{c}\text { Average } \\
\text { discount size }\end{array}$ \\
\hline All MNOs & 1135 & 697 & $61 \%$ & $51 \%$ \\
Large MNOs & 568 & 427 & $75 \%$ & $49 \%$ \\
Small MNOs & 567 & 270 & $48 \%$ & $55 \%$ \\
MVNOs & 327 & 47 & $14 \%$ & $80 \%$ \\
\hline Total & 1462 & 744 & $51 \%$ & $53 \%$
\end{tabular}

Notes: Average discount size is the average difference between on-net and off-net prices as a percent of off-net price (only tariffs with non-zero discounts). 


\begin{tabular}{|c|c|c|c|c|c|c|}
\hline & \multicolumn{3}{|c|}{ Prob. discount is given (logit) } & \multicolumn{3}{|c|}{ Size of discount (OLS) } \\
\hline & $(5-1)$ & $(5-2)$ & $(5-3)$ & $(5-4)$ & $(5-5)$ & $(5-6)$ \\
\hline & Baseline & $\begin{array}{c}\text { Current } \\
\text { tariffs }\end{array}$ & $\begin{array}{c}\text { Small vs. } \\
\text { large }\end{array}$ & Baseline & $\begin{array}{c}\text { Current } \\
\text { tariffs }\end{array}$ & $\begin{array}{l}\text { Small vs. } \\
\text { large }\end{array}$ \\
\hline MNO & $\begin{array}{c}0.260 * * * \\
(0.089)\end{array}$ & $\begin{array}{c}0.325 * * * \\
(0.091)\end{array}$ & & $\begin{array}{c}-0.169 * \\
(0.083)\end{array}$ & $\begin{array}{c}-0.166^{* *} \\
(0.075)\end{array}$ & \\
\hline Small MNO & & & $\begin{array}{c}0.119 \\
(0.111)\end{array}$ & & & $\begin{array}{l}-0.192 \\
(0.114)\end{array}$ \\
\hline Large MNO & & & $\begin{array}{c}0.375 * * * \\
(0.137)\end{array}$ & & & $\begin{array}{l}-0.151 * \\
(0.073)\end{array}$ \\
\hline Termination Fees & $\begin{array}{c}0.460 \text { *** } \\
(0.107)\end{array}$ & $\begin{array}{c}0.011^{* *} \\
(0.005)\end{array}$ & $\begin{array}{c}0.132 \\
(0.259)\end{array}$ & $\begin{array}{l}-0.064 \\
(0.041)\end{array}$ & $\begin{array}{c}0.002 \\
(0.003)\end{array}$ & $\begin{array}{c}-0.100^{*} \\
(0.054)\end{array}$ \\
\hline Market: Basic & $\begin{array}{c}0.223 * * * \\
(0.041)\end{array}$ & $\begin{array}{c}0.197 * * * \\
(0.050)\end{array}$ & $\begin{array}{c}0.218 * * * \\
(0.041)\end{array}$ & $\begin{array}{l}-0.005 \\
(0.023)\end{array}$ & $\begin{array}{l}-0.010 \\
(0.026)\end{array}$ & $\begin{array}{c}-0.004 \\
(0.023)\end{array}$ \\
\hline Market: Average & $\begin{array}{c}0.088 * \\
(0.049)\end{array}$ & $\begin{array}{c}0.092 * * \\
(0.041)\end{array}$ & $\begin{array}{c}0.085^{*} \\
(0.047)\end{array}$ & $\begin{array}{c}-0.038 * * * \\
(0.011)\end{array}$ & $\begin{array}{c}-0.048 \\
(0.029)\end{array}$ & $\begin{array}{c}-0.038 * * * \\
(0.011)\end{array}$ \\
\hline Market: Heavy & $\begin{array}{l}0.136 * \\
(0.073)\end{array}$ & $\begin{array}{l}0.119 * \\
(0.070)\end{array}$ & $\begin{array}{c}0.138 * * \\
(0.069)\end{array}$ & $\begin{array}{c}0.149 * * * \\
(0.036)\end{array}$ & $\begin{array}{c}0.120 * * \\
(0.051)\end{array}$ & $\begin{array}{c}0.152 * * * \\
(0.034)\end{array}$ \\
\hline Year dummies & Yes & Yes & Yes & Yes & Yes & Yes \\
\hline Obs. level & Tariff & $\begin{array}{l}\text { Tariff- } \\
\text { quarter }\end{array}$ & Tariff & Tariff & $\begin{array}{l}\text { Tariff- } \\
\text { quarter }\end{array}$ & Tariff \\
\hline S.E. clusters & Firm & Tariff & Firm & Firm & Tariff & Firm \\
\hline Observations & 1,462 & 6,168 & 1,462 & 744 & 3,541 & 744 \\
\hline R-squared & & & & 0.306 & 0.306 & 0.308 \\
\hline
\end{tabular}

Notes: Baseline specifications (5-1) and (5-4) test for differences in tariff choices between MNOs and MVNOs (base category). Specifications (5-2) and (5-5) use the sample of all currently offered tariffs (on a quarterly level) instead of sampling tariffs only at the time of their introduction. The MNO effect is then split up into an effect of small MNOs (E-Plus and O2) and of large MNOs (TMobile and Vodafone) in specifications (5-3) and (5-6). Standard errors clustered at the firm level $(5-1,5-3,5-4,5-6)$ or at the tariff level $(5-2,5-5)$ are in parentheses. Asterisks denote significance levels $(* * * \mathrm{p}<0.01, * * \mathrm{p}<0.05, * \mathrm{p}<0.1)$. For logit models average marginal effects are reported (hence no coefficient for constant). Constants for the OLS models and coefficients for year fixed effects are not reported. The base category for markets is Rare Users. The base category for operator size is $M V N O$. 
Table 6: Robustness Tests

\begin{tabular}{|c|c|c|c|c|c|c|}
\hline & \multicolumn{3}{|c|}{ Prob. discount is given (logit) } & \multicolumn{3}{|c|}{ Size of discount (OLS) } \\
\hline & $\begin{array}{c}\text { (6-1) } \\
\text { Tariff } \\
\text { elements }\end{array}$ & $\begin{array}{c}(6-2) \\
\text { Market } \\
\text { shares }\end{array}$ & $\begin{array}{c}\text { (6-3) } \\
\text { Reduced } \\
\text { sample }\end{array}$ & $\begin{array}{c}\text { (6-4) } \\
\text { Tariff } \\
\text { elements }\end{array}$ & $\begin{array}{c}(6-5) \\
\text { Market } \\
\text { shares }\end{array}$ & $\begin{array}{c}(6-6) \\
\text { Reduced } \\
\text { sample }\end{array}$ \\
\hline MNO & $\begin{array}{c}0.324 * * * \\
(0.063)\end{array}$ & & $\begin{array}{c}0.244 * * \\
(0.099)\end{array}$ & $\begin{array}{l}-0.123 \\
(0.089)\end{array}$ & & $\begin{array}{l}-0.141 \\
(0.087)\end{array}$ \\
\hline Market Share & & $\begin{array}{c}1.119 \\
(1.080)\end{array}$ & & & $\begin{array}{l}-0.000 \\
(0.362)\end{array}$ & \\
\hline Termination Fees & $\begin{array}{c}0.441 * * * \\
(0.122)\end{array}$ & $\begin{array}{c}0.196 \\
(0.420)\end{array}$ & $\begin{array}{c}0.390 * * * \\
(0.135)\end{array}$ & $\begin{array}{c}0.002 \\
(0.043)\end{array}$ & $\begin{array}{l}-0.060 \\
(0.063)\end{array}$ & $\begin{array}{c}-0.208 * * \\
(0.094)\end{array}$ \\
\hline $\begin{array}{l}\text { Runtime contract } \\
\text { (dummy) }\end{array}$ & $\begin{array}{c}0.068 \\
(0.054)\end{array}$ & & & $\begin{array}{c}0.049 \\
(0.048)\end{array}$ & & \\
\hline $\begin{array}{l}\text { Base Fee } \\
\quad \text { (dummy) }\end{array}$ & $\begin{array}{c}0.099 \\
(0.071)\end{array}$ & & & $\begin{array}{l}-0.122 \\
(0.095)\end{array}$ & & \\
\hline $\begin{array}{l}\text { Free Minutes } \\
\quad \text { (dummy) }\end{array}$ & $\begin{array}{c}-0.369 * * * \\
(0.061)\end{array}$ & & & $\begin{array}{c}-0.264 * * * \\
(0.032)\end{array}$ & & \\
\hline Market: Basic & $\begin{array}{c}0.140 * * * \\
(0.054)\end{array}$ & $\begin{array}{c}0.157 * * * \\
(0.022)\end{array}$ & $\begin{array}{c}0.357 * * * \\
(0.079)\end{array}$ & $\begin{array}{l}0.072^{*} \\
(0.040)\end{array}$ & $\begin{array}{l}-0.014 \\
(0.022)\end{array}$ & $\begin{array}{l}-0.052 \\
(0.070)\end{array}$ \\
\hline Market: Average & $\begin{array}{c}0.063 \\
(0.051)\end{array}$ & $\begin{array}{c}0.002 \\
(0.040)\end{array}$ & $\begin{array}{c}0.219 * * \\
(0.098)\end{array}$ & $\begin{array}{c}0.082 * * \\
(0.035)\end{array}$ & $\begin{array}{c}-0.040 * * \\
(0.010)\end{array}$ & $\begin{array}{c}-0.172 * * \\
(0.057)\end{array}$ \\
\hline Market: Heavy & $\begin{array}{c}0.069 \\
(0.049)\end{array}$ & $\begin{array}{c}0.025 \\
(0.074)\end{array}$ & $\begin{array}{c}0.268 * * \\
(0.126)\end{array}$ & $\begin{array}{c}0.221 * * * \\
(0.055)\end{array}$ & $\begin{array}{c}0.122 * * \\
(0.025)\end{array}$ & $\begin{array}{c}0.077 \\
(0.078)\end{array}$ \\
\hline Year dummies & Yes & Yes & Yes & Yes & Yes & Yes \\
\hline $\begin{array}{l}\text { Observations } \\
\text { R-squared }\end{array}$ & 1,462 & 1,135 & 958 & $\begin{array}{c}744 \\
0.306\end{array}$ & $\begin{array}{c}697 \\
0.306\end{array}$ & $\begin{array}{c}384 \\
0.308\end{array}$ \\
\hline
\end{tabular}

Notes: Specifications (6-1) and (6-4) consider additional tariff elements. Specifications (6-2) and (6-5) include only MNOs and test for the influence of their market shares. Finally, specifications (6-3) and (6-6) include only tariffs launched after 2004. Standard errors clustered at the firm level are in parentheses. Asterisks denote significance levels $(* * * \mathrm{p}<0.01, * * \mathrm{p}<0.05, * \mathrm{p}<0.1)$. For logit models average marginal effects are reported (hence no coefficient for constant). Constants for the OLS models and coefficients for year fixed effects are not reported. The base category for markets is Rare Users. The base category for operator size is MVNO. 


\section{Appendix A - Supplementary Material}

\section{Allocation of Tariffs to Markets}

Mobile phone tariffs are obviously targeted at very different market segments, e.g. occasional callers and heavy usage business users. Treating all tariffs as competing equally for the same consumers could skew our results, so we allocated each tariff to a unique market segment. This is achieved using three standard usage baskets defined by the German Federal Statistical Agency (2006) for 'rare', 'low' and 'average' cellular phone users. No basket was available for business users, so we defined a 'heavy' user basket as an inflated version of the average user basket. The assumptions baskets are detailed in Table A1.

\section{Table A1: Usage baskets}

Usage in minutes (monthly values calculated with BNA baskets of 2000)

Assumption: Call duration constant over different types

\begin{tabular}{|c|c|c|c|c|c|}
\hline & Unit & $\begin{array}{l}\text { Rare } \\
\text { users }\end{array}$ & $\begin{array}{c}\text { Low-level } \\
\text { users }\end{array}$ & $\begin{array}{c}\text { Average } \\
\text { users }\end{array}$ & $\begin{array}{l}\text { Heavy } \\
\text { users* }\end{array}$ \\
\hline Total duration of calls & $\min$ & 20 & 60 & 200 & 600 \\
\hline $\mathrm{o} / \mathrm{w}$ to own network & $\min$ & 7 & 27 & 69 & 207 \\
\hline $\mathrm{o} / \mathrm{w}$ to other network & $\min$ & 4 & 9 & 40 & 120 \\
\hline $\mathrm{o} / \mathrm{w}$ to fixed-line & $\min$ & 9 & 24 & 91 & 273 \\
\hline$\overline{\mathrm{SMS}}$ & $\#$ & 20 & 60 & 60 & 180 \\
\hline
\end{tabular}

Each tariff was allocated to a unique basket ('market') with the following procedure:

1. Calculate the monthly cost of each tariff for each of the four user baskets using the tariff components and the usage pattern for the baskets.

2. Using all tariffs, identify the lower $10 \%$-ile in terms of cost for each user basket by month.

3. Calculate the relative distance of each tariff's cost to the lower cost percentile for each user basket in the month it was introduced.

4. Allocate each tariff to the basket where the relative distance is smallest.

In calculating the monthly cost we make two simplifying assumptions. First, we assume calls are distributed evenly over the day. In the period covered by our dataset a decreasing number of tariffs differentiate between different times of day; where different rates were offered we used the average cost. Second, if off-net prices varied for different operators we 
used the average off-net price. This affected a negligible percentage of the tariffs in the sample.

The results of the tariff allocation for average monthly user bills are provided in Table A2. A potential weakness of the market allocation procedure is that the user baskets were only available for 2000. In the time between then and the end of our dataset there may have been changes in usage patterns arising endogenously from increasing diffusion and falling prices.

Table A2: Tariff Allocation

Results of Tariff Allocation to Markets

Observations and monthly user bill in EUR

\begin{tabular}{lccccc} 
Market & Obs. & Mean & SD & Min & Max \\
\hline Rare & 231 & 10.26 & 6.35 & 2.00 & 29.58 \\
Low & 372 & 41.65 & 12.04 & 14.82 & 73.99 \\
Average & 352 & 66.25 & 24.00 & 26.00 & 138.73 \\
Heavy & 507 & 141.25 & 55.64 & 9.00 & 365.10 \\
\hline Total & 1,462 & 77.15 & 61.13 & 2.00 & 365.10
\end{tabular}

However, the allocation was robust towards a wide range of inflation factors for the heavy user basket and towards using fiscal quarters rather than months to define the lower cost quartile. Results were also robust towards using lower percentiles between 5\% and $15 \%$. The $10 \%$-ile level was chosen because it yielded the most plausible allocation based on a qualitative investigation of tariff names. The lists allocating the tariffs to the markets are available on request from the authors.

\section{Data Cleaning}

The data gathered by Teltarif were subjected to extensive cleaning at the operator and tariff levels. At the operator level non-mobile operators were excluded from the dataset, e.g. a data-service company offering tariffs as an add-on for companies implementing software solutions. Three operators who had only a few $(<3)$ tariffs and for whom no information could be found on the internet were also dropped from the dataset. Finally, 23 tariff resellers were dropped, as discussed in detail in the paper.

At the tariff level the following tariffs were dropped to avoid distortions in price calculations and the calculated number of new tariffs: Bundles whose price covered both a mobile tariff and a broadband access, bundles including both mobile and fixed-line tariffs, add-on options for tariffs (such as 'Extra 100 free SMS'), and pure data tariffs for mobile devices (without calling functionality). Furthermore, we eliminated duplicate tariffs, i.e. 
identical tariffs offered by the same operator over the same time period under a different name, as these did not pose a substantially new offering for consumers.

Note that tariffs are also influenced by firms' strategy of attracting new subscribers by subsidizing mobile handsets and subsequently recovering their investment over the duration of the tariff contract. While we cannot control for this effect due to a lack of data on handset subsidies, we see no reason why this should systematically influence the on-net / off-net price differential over and above the robustness tests reported in the paper. 